\title{
Highly-Sensitive Graphene-based Flexible Pressure Sensor Platform
}

(Pentas Sensor Tekanan Fleksibel Sensitif Berasaskan Grafin)

\author{
MuHAMMAD ANIQ SHAZNI, MAI WoOn LEE \& Hing WAH LEE*
}

\begin{abstract}
In this work, graphene has been utilized as the sensing material for the development of a highly-sensitive flexible pressure sensor platform. It has been demonstrated that a graphene-based pressure sensor platform that is able to measure pressure change of up to 3 psi with a sensitivity of $0.042 \mathrm{psi}^{-1}$ and a non-linearity of less than $1 \%$ has been accomplished. The developed device, which resides on a flexible platform, will be applicable for integration in continuous wearables health-care monitoring system for the measurement of blood pressure.
\end{abstract}

Keywords: Chemical vapor deposition (CVD); flexible; graphene; interdigitated electrodes (IDE); pressure sensor; wearables

\section{ABSTRAK}

Dalam kajian ini, grafin telah digunakan sebagai bahan penderiaan untuk pembangunan pentas fleksibel untuk penderia tekanan darah yang sangat sensitif. Ia telah dibuktikan bahawa sebuah pentas penderia tekanan yang berasaskan grafin berupaya untuk mencapai pengukuran perubahan tekanan sehingga 3 psi dengan kepekaan 0.042 psi $^{-1}$ dan ketidaklinearan yang kurang daripada 1\%. Penderia yang telah dibangunkan ini sesuai untuk digunakan dalam sistem boleh guna pemantauan tekananan darah secara berterusan bagi industri penjagaan kesihatan.

Kata kunci: Boleh guna; elektrod interdigit (IDE); fleksibel; grafin; pemendapan wap kimia (CVD); penderia tekanan

\section{INTRODUCTION}

For the year 2008, the World Health Organization had published its statistics on the major causes of deaths throughout the world and had reported Ischaemic heart disease as the top killer with 7.28 million deaths which accounts for approximately $12.8 \%$ of all disease related deaths. Ischaemic heart disease relates to the blood flow to the heart whereby poor or irregular flow is proven to lead to cardiovascular illnesses. As the technology advances, it paves the road to create new scientific applications that most of them were not feasible with the older technologies. Miniaturized pressure sensors have many potential usage in advanced biomedical and health-care applications such as intravascular blood pressure sensing, continuously monitoring of intraocular (within the eye) pressure in glaucoma patients and implanted intra-abdominal pressure monitoring to name a few. There has been an increasing interest in research on ultra-miniaturized, ultrasensitive, ultra-low power, fast, portable and robust pressure sensors recently to be integrated into a wireless wearable sensor system or smart clothing platform for continuous monitoring. Nanotechnology is a great enabler for many applications in various fields including sensor industries and biomedical applications. Pressure sensor is one of the devices that has benefited from the nanotechnology advancement.

In order to have ultra-low power and minimally invasive medical systems, the sensors and the peripherals must be ultra-miniaturized. The conventional technologies such as diaphragm technology and MEMS have some fabrication limitation that does not allow extra miniaturization of the device. However, incorporating nanomaterials would allow further reduction of the size of pressure sensors.

Lanotte et al. (2004) demonstrated the correlation between strain and electric conduction in composite materials made of nano magnetic particles. They focused on the theoretical and experimental correlation of the material elasticity with its magnetic behaviour and electric conduction. A change of the magnetizing field along an axis different from the easy magnetization (which is the permanent magnetization axis when the filling particles are permanently magnetized) gives a rotation of the particles due to the mechanical torque, in order to align the magnetic moments with the applied field. This effect is named 'direct elastomagnetic effect' and the macroscopic effect of these local rotations can be a deformation of the whole material. In a constant external magnetic field and fixed temperature, the inverse effect can be used as a strain sensing technique in which the deformation of the material would change its magnetic behaviour.

Kesapragada et al. (2006) reported the indication of potential application of $\mathrm{Cr}$ nanosprings as pressure sensing materials. They grew arrays of $\mathrm{Cr}$ zigzag nanosprings and slanted nanorods, $15-55 \mathrm{~nm}$ and 40-80 nm-wide, respectively, on $\mathrm{SiO} 2 / \mathrm{Si}$ substrates by glancing angle deposition. They claimed that the arrays exhibit a reversible 
change in resistivity upon loading and unloading, by $50 \%$ for nanosprings and $5 \%$ for nanorods. They tested their device in loading and unloading modes with a loading pressure of $800 \mathrm{kPa}$. Although their device was responding to the change in pressure however its response was not so stable.

A multi-physics model incorporating thermionic emission, thermionic field emission and tunneling as the current transport mechanisms to quantify the influence of thermopiezoelectric effects in nano-sized AlxGa1-xN/GaN heterostructures has also been demonstrated for pressure sensor applications based on the barrier height modulation principle (Patil et al. 2009). They used a fully coupled thermoelectromechanical formulation, consisting of balance equations for heat transfer, electrostatics and mechanical field. Their simulations suggest that AlxGa1-xN/GaN heterostructure-based devices are promising candidates for pressure sensor applications under severe environmental conditions.

The researchers at RTH, Zurich have worked on realization of ultra-miniature pressure sensor from 20062010. They reported fabrication of a nano pressure sensor using a single wall carbon nanotube (SWCNT) on a thin membrane of $40 \mu \mathrm{m}$ diameter (Helbling et al. 2009). Their sensors consisted of a double layer membrane made of $\mathrm{SiO}_{2}$ and atomic layer deposited (ALD) alumina $\left(\mathrm{Al}_{2} \mathrm{O}_{3}\right)$. The SWNT strain gauges were embedded between the bottom $\mathrm{SiO}_{2}$ and the top $\mathrm{Al}_{2} \mathrm{O}_{3}$ layer and contacted in a field effect transistor configuration.

They used the top and bottom oxide layers to encapsulate the SWNTs to protect the SWNTs from the environment. Although some research have been initiated on the realization of nano pressure sensors, only a few nano materials have been tried out such as SWCNT and $\mathrm{Cr}$ nano springs.

At recent time, the development of nanosensors incorporating graphene is a promising line of research as the sensors can be designed to take advantage of the unique electro-mechanical properties of graphene. However, in order to design the nanosensors, the electrical and mechanical properties of graphene have to be understood. Early research works have been performed by researchers to characterize and understand the properties of the graphene as shown by Castellanos-Gomez et al. (2012), Gómez-Navarro et al. (2008) and Huang et al. (2011). The works performed by these researchers elucidated that graphene sheet exhibits extraordinary stiffness ( $\mathrm{E}=0.25 \mathrm{TPa})$ whereas they present low pre-strain and high strength which enabled them to withstand elastic deformations of tens of nanometers elastically without breaking. In view of that, the low pre-tension and high elasticity and Young's modulus of these crystals make graphene an attractive substitute in applications requiring flexible semiconductor materials.

The superior mechanical property of the graphene material has thus attracted the attention of researchers to incorporate them for sensors applications. However, more efforts have been emphasized on the design and modelling of the graphene materials for pressure sensing applications (Jun et al. 2011; Kwon et al. 2013; Sorkin \& Zhang 2011).
Sorkin and Zhang (2011) constructed a simple atomistic model for graphene nanoflakesilicon carbide-based pressure nanosensor in which the failure behavior of the sensor under an applied pressure has been investigated. Meanwhile, Jun et al. (2011) observed a nonlinear elastic softening of the graphene with an increase of hydrogen pressure due to the stretching and weakening of the carbon-carbon bonds by performing constant-temperature molecular dynamics (MD) simulations. Kwon et al. (2013) also established a molecular dynamic simulations model to investigate the electro-mechanical properties of the graphene-nanoribbon for the purpose of developing an ultra-sensitive pressure sensor.

For the development of graphene-based pressure sensor, one of the earlier works has been demonstrated by Bunch et al. (2007) where a prototype for pressure sensor has been demonstrated by placing a graphene flake over a well in silicon dioxide. The permeability of graphene was investigated by applying pressure difference across the graphene sheet and it was found that the graphene flake is impermeable to standard gases. It was thus demonstrated that graphene flake can be utilized for pressure sensing applications which further entice the attention of the research community involved in graphene-based research works. Following this novel experimental fabrication and manipulation of graphene as NEMS components, several other studies have explored the mechanical (Frank et al. 2007; Poot \& van der Zant 2008) and electromechanical response of these systems (Chen et al. 2009, Milaninia et al. 2009). Additionally, Singh et al. (2010) conducted experimental works to evaluate the effects of uniaxial strains in isolated graphene nanoribbons.

It is apparent that the researchers have started to look into the applications and incorporation of graphene into sensors and devices to take advantage of its inherent superior mechanical and electrical properties. However, researchers conducted are still at an early stage and there has not been any reported robust or manufacturable graphene-based sensors or devices developed to date.

In terms of pressure sensing, some researches have been initiated on the realization of nano pressure sensors incorporating nanomaterials such as SWCNT (Hebling et al. 2009) and Cr nano springs (Kesapragada et al. 2006) but no robust graphene-based. In this project, the researchers proposes to research and develop a passive and highly sensitive pressure sensor platform for wearable health care monitoring application comprising a thin flexible membrane and incorporating graphene nanomaterial as its flexible sensing element where the electrical conductivity of the nano-layer graphene changes with applied mechanical stress.

\section{MATERIALS AND METHODS}

For this work, a standard flat square membrane has been incorporated as the membrane structure for the pressure sensor device. The design of the flexible membrane as shown in Figure 1 comes with the dimensions of a $5 \mathrm{~mm}$ 


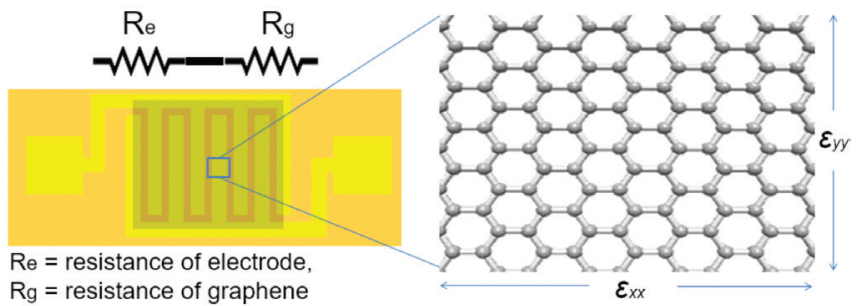

FIGURE 1. A schematic view of flexible graphene pressure sensor modeling with the corresponding membrane and IDE dimensions (Membrane length $=L_{g}$, Membrane width $=W_{g}$, membrane thickness $=t$, $\operatorname{IDE}$ length $=l_{e}$, IDE width $=w_{e}$, IDE gap $=g_{e}$ )

$\left(L_{g}\right) \times 5 \mathrm{~mm}\left(W_{g}\right)$ with uniform thickness of $130 \mu \mathrm{m}(t)$ while the interdigitated electrodes (IDE) comes with the optimized size of $4000 \mu \mathrm{m}$ (length), $600 \mu \mathrm{m}$ (width) and $200 \mu \mathrm{m}$ (gap). The design of the flexible pressure sensor platform and its corresponding IDE structures have been fabricated on flexible polyimide substrates with copper electrodes. The fabricated platform is as illustrated in Figure 2.

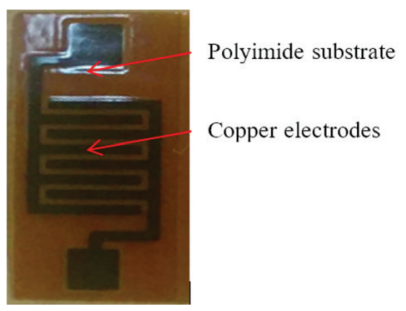

FIGURE 2. Fabricated flexible graphene pressure sensor platform

Once the flexible graphene pressure sensor platform has been fabricated, graphene on copper foil will be transferred and incorporated onto the platform. The optimised graphene transfer platform is shown in Figure 3 . The full descriptions of the graphene transfer process is as follow:
Graphene on copper foil is synthesized based on chemical vapour deposition (CVD) method. A thin layer of PMMA polymer of $15 \mu \mathrm{m}$ is spin coated on top of the graphene layer. The samples are then left into a ferric chloride solution for at least $6 \mathrm{~h}$ to remove the copper $(\mathrm{Cu})$ catalyst layer. After the full removal of the $\mathrm{Cu}$ catalyst layer, the graphene with PMMA floating on top of the solution will be transferred on top of the developed flexible pressure sensor platform. The whole device will then be left into acetone solution to remove the PMMA layer. After full removal of the PMMA layer, the samples will be cleaned with IPA and dried through nitrogen air.

The developed flexible pressure sensor platform incorporated with graphene will then be analysed with optical microscopy, atomic force microscopy (AFM) and Raman characterisations to check the surface morphology and quality of the transferred graphene layer.

Once graphene has been incorporated on the flexible pressure sensor platform, the device will be tested against the change in the applied pressure on the platform using a newly developed test setup which consisted of a test jig, pressure regulation system and electrical connection for electrical characterizations as shown in the schematic diagram of Figure 4 while the actual in-house developed test setup is demonstrated in Figure 5.

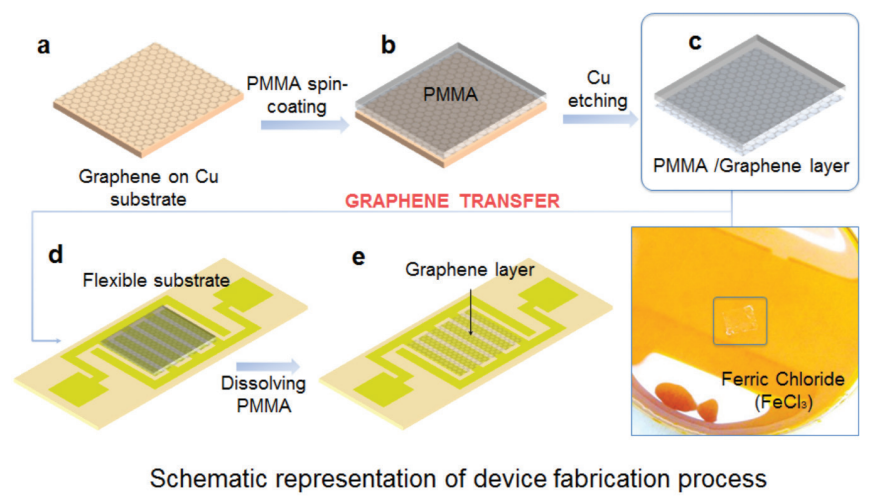

FIGURE 3. Optimised graphene transfer process on top of the fabricated flexible graphene pressure sensor platform 


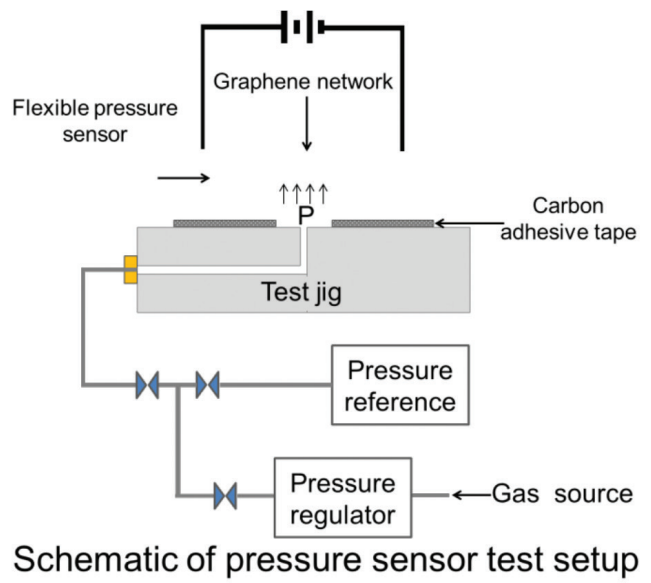

FIGURE 4. Schematic of the test setup for device characterisation and testing

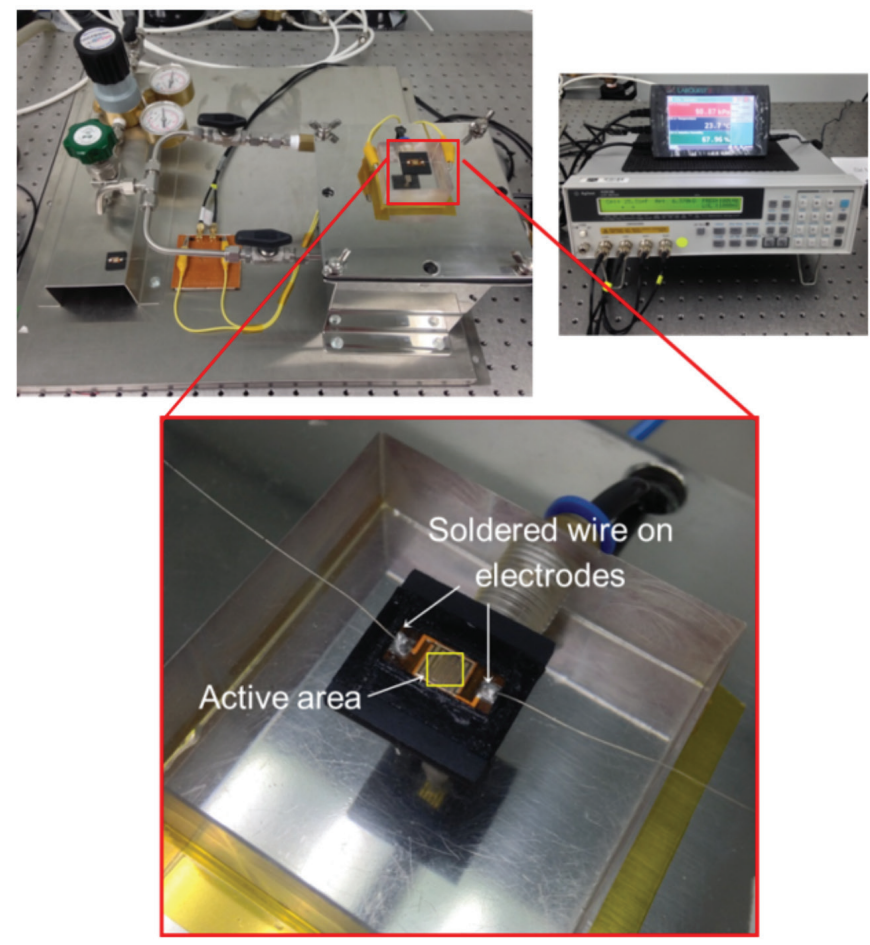

FIGURE 5. Actual test setup in MIMOS laboratory

\section{RESULTS AND DISCUSSION}

The results from the Raman characteristics in Figure 6 shows that graphene has been successfully transferred onto the flexible pressure sensor platform. Optical imaging of the graphene transferred on the IDE platform is described in Figure 7(a) where in the close-up imaging, it can be observed that there exist what we believed to be some instances of cracks and wrinkles on the transferred graphene surface as illustrated in Figure 7(b) and 7(c). AFM imaging as illustrated in Figure 7(d) further confirms the existence of these surface features on the transferred graphene.

Upon application of external pressure on the flexible pressure sensor platform on the test setup, it can be observed that a meaningful change in the electrical resistance occurred. The change in the electrical resistance of the IDE network with graphene on the pressure sensor platform is summarized in Figure 8 for an application of external pressure of up to $3 \mathrm{psi}$, which corresponds to the typical highest blood pressure range allowed in normal human body. It is believed that the ability of the device to exhibit a large change in the electrical resistance based on the applied pressure is mainly due to the discontinuity in the network of the graphene sensing material similar to the work performed by Gau et al. (2009), Luheng et al. (2009) and Yao et al. (2013). In view of that, for pressure sensing applications, it is advisable that cracks, wrinkles or imperfections in the morphology of the graphene sensing material are introduced. 


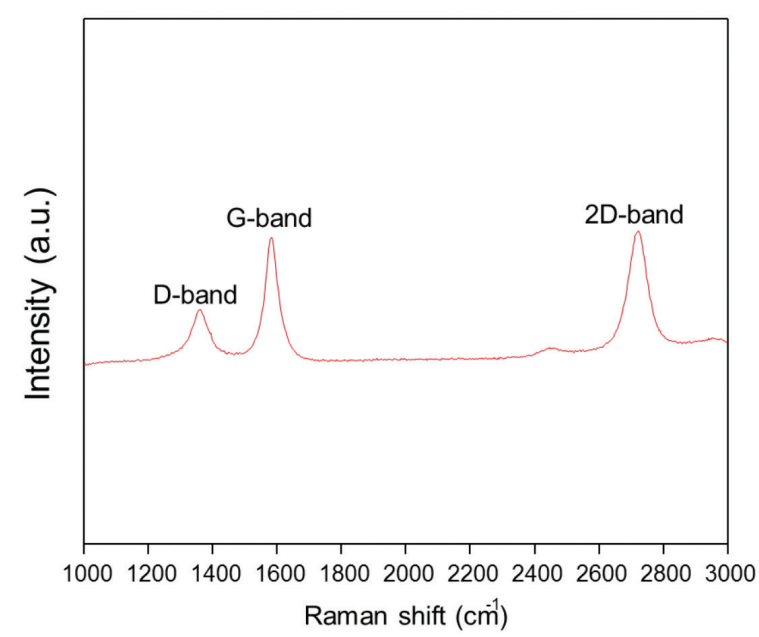

FIGURE 6. Raman characterisations of the transferred multi-layer Graphene showing the signature D-, G- and 2D-band associated with typical graphene material
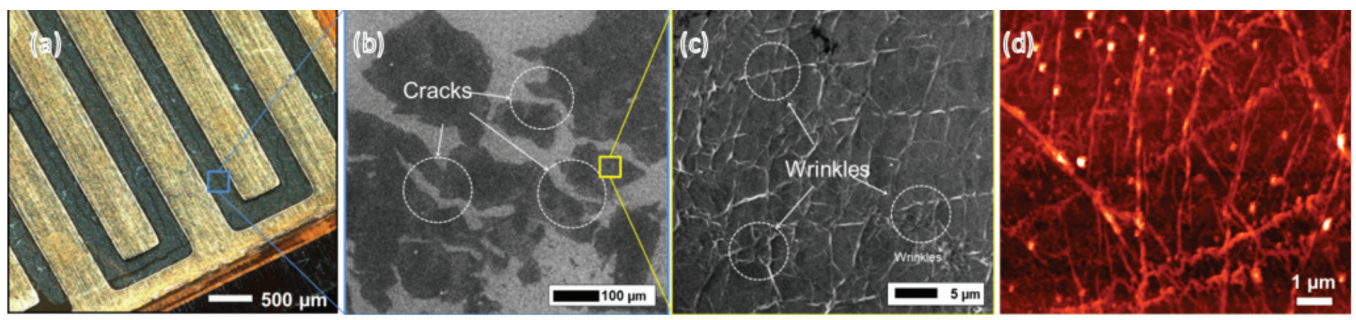

FIGURE 7. Morphological characteristics of graphene on flexible pressure sensor: (a) Optical images, (b) FESEM images of graphene network (c) Close-up view images and (d) AFM images of graphene network

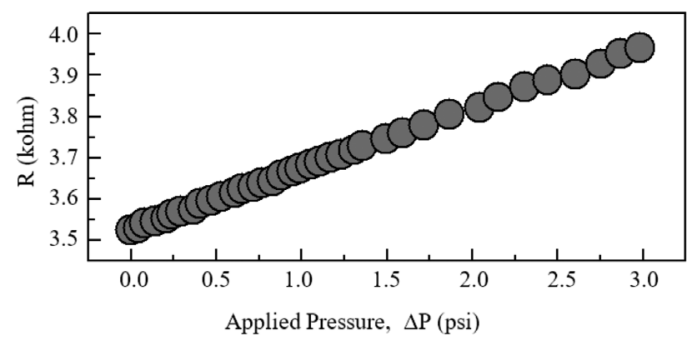

FIGURE 8. Resistance-dependence of pressure for graphene-based pressure sensor

The total resistance of the graphene-based pressure sensor can be given by:

$$
\begin{aligned}
& \mathrm{R}_{\mathrm{T}}=\mathrm{R}_{\mathrm{e}}+\mathrm{R}_{\mathrm{g}} \\
& \mathrm{R}_{\mathrm{T}}=\rho_{\mathrm{e}} \frac{\mathrm{L}_{\mathrm{e}}}{\mathrm{A}_{\mathrm{e}}}+\rho_{\mathrm{g}} \frac{\mathrm{L}_{\mathrm{g}}}{\mathrm{W}_{\mathrm{g}}} .
\end{aligned}
$$

Hence the resistance under deformation as a function of strain can be defined by:

$$
\mathrm{R}_{\mathrm{T}}(\varepsilon)=\left(\rho_{\mathrm{e}}+\Delta \rho_{\mathrm{e}}\right) \frac{L_{\mathrm{e}}+\Delta L_{e}}{A_{\mathrm{e}}+\Delta A_{e}}+\frac{1}{2 q N_{\mathrm{e}}(\varepsilon) \mu_{\mathrm{e}}(\varepsilon)} \frac{\left(1+\varepsilon_{x x}\right) L_{g}}{\left(1+\varepsilon_{y y}\right) W_{g}},
$$

where $\rho \mathrm{e}$ is the resistivity of electrode; $\rho \mathrm{g}$ is the resistivity of graphene; $q$ is the positive electron charge; $N \mathrm{e}$ is the electron density; $\mu \mathrm{e}$ is the electron mobility; $\varepsilon \mathrm{xx}$ is the longitudinal strain; and $\varepsilon y y$ is the transverse strain.

Meanwhile the sensitivity, $\mathrm{S}$ is defined as the relative change of output voltage per unit of applied pressure with the unit of $\mathrm{mV} / \mathrm{Vpsi}$ or $\mathrm{psi}^{-1}$ and can be expressed by Bao (2000).

$$
\mathrm{S}=\frac{\Delta \mathrm{V}}{\mathrm{V} \cdot \mathrm{P}}
$$

It could be observed that the developed graphenebased pressure sensor exhibited a very good sensitivity response of $0.042 \mathrm{psi}^{-1}$ with a non-linearity of less than $1 \%$ as shown in Figure 9.

In order to test the reliability of the developed pressure sensor, the device is subjected to cyclic loading of pressure change of 2.1 psi of more than 10 cycles. The sensor is able to respond consistently to the change of the pressure as the diaphragm is able to elastically return to its initial form upon release of the applied external pressure as illustrated in Figure 10.

\section{CONCLUSION}

It has been demonstrated that a graphene-based pressure sensor on a flexible platform for highly sensitive blood 


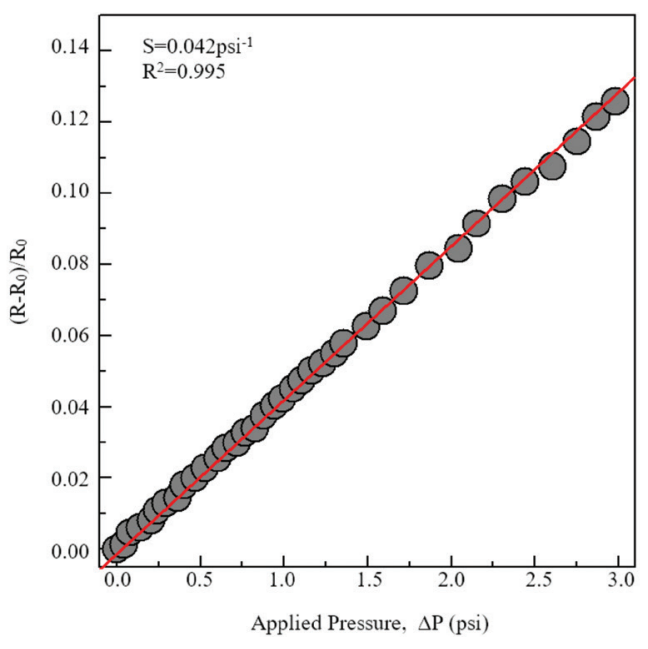

FIGURE 9. Sensitivity-dependence of pressure for graphene-based pressure sensor

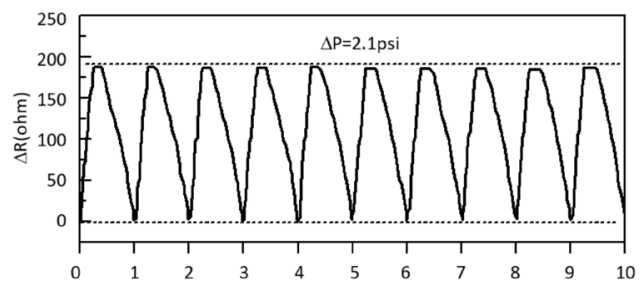

FIGURE 10. Multiple-cycle operation of repeated loading and unloading pressure

pressure measurement has been accomplished in which it is able to measure within the required change in the blood pressure sensor of up to 3 psi with a sensitivity of $0.042 \mathrm{psi}^{-1}$ and a non-linearity of less than $1 \%$. The developed device will be applicable for integration in continuous wearable health-care monitoring system for the measurement of blood pressure. It should also be noted that due to the continuous nature of the graphene sensing material, it is advisable that cracks, wrinkles or imperfections in its morphology are introduced in order for a meaningful change in the electrical response upon application of external pressure is achieved.

\section{ACKNOWLEDGEMENTS}

This research was supported by the eScience Funding 0303-04-SF0064 under the Ministry of Science, Technology, and Innovation (MOSTI), Malaysia.

\section{REFERENCES}

Bao, M. 2000. Micro mechanical transducer - pressure sensors. Accelerometers and Gyroscopes. New York: Elsevier.

Bunch, J.S., Van der Zande, A.M., Verbridge, S.S., Frank, I.W., Tanenbaum, D.M., Parpia, J.M., Craighead, H.G. \& McEuen, P.L. 2007. Electromechanical resonators from graphene sheets. Science 315(5811): 490-493.

Castellanos-Gomez, A., Poot, M., Steele, G.A., Van der Zant, H.S.J., Agraït, N. \& Rubio-Bollinger, G. 2012. Mechanical properties of freely suspended semiconducting graphene-like layers based on $\mathrm{MoS}_{2}$. Nanoscale Research Letters 7: 233.

Chen, C., Rosenblatt, S., Bolotin, K.I., Kalb, W., Kim, P., Kymissis, I., Stormer, H.L., Heinz, T.F. \& Hone, J. 2009. Performance of monolayer graphene nanomechanical resonators with electrical readout. Nature Nanotechnology 4(12): 861-867.

Frank, I.W., Tanenbaum, D.M., Van der Zande, A.M. \& McEuen, P.L. 2007. Mechanical properties of suspended graphene sheets. Journal of Vacuum Science \& Technology B, Nanotechnology and Microelectronics: Materials, Processing, Measurement, and Phenomena 25(6): 2558-2561.

Gau,C., Ko,H.S. \& Chen,H.T. 2009. Piezoresistive characteristics of MWNT nanocomposites and fabrication as a polymer pressure sensor. Nanotechnology 20: 185503.

Gómez-Navarro, C., Burghard, M. \& Kern, K. 2008. Elastic properties of chemically derived single graphene sheets. Nanoletters 8(7): 2045-2049.

Helbling, T., Drittenbass, S., Durrer, L., Roman, C. \& Hierold, C. 2009. Ultra small single walled carbon nanotube pressure sensors. IEEE 22nd International Conference on Micro Electro Mechanical Systems. pp. 575-578.

Huang, X., Yin, Z., Wu, S., Qi, X., He, Q., Zhang, Q., Yan, Q., Boey, F. \& Zhang, H. 2011. Graphene-based materials: Synthesis, characterization, properties, and applications. Small 7(14): 1876-1902.

Jun, S., Tashi, T. \& Park, H.S. 2011. Size dependence of the nonlinear elastic softening of nanoscale graphene monolayers under plane-strain bulge tests: A molecular dynamics study. Journal of Nanomaterials (Special Issue) 2011: Article No. 15.

Kesapragada, S.V., Victor, P., Nalamasu, O. \& Gall, D. 2006. Nanospring pressure sensors grown by glancing angle deposition. Nano Letters 6(4): 854-857.

Kwon, O.K.,Lee, J.H., Kim, K.S. \& Kang, J.W. 2013. Developing ultrasensitive pressure sensor based on graphene nanoribbon: Molecular dynamics simulation. Physica E: Low-dimensional Systems and Nanostructures 47: 6-11.

Lanotte, L., Ausanio, G., Hison, C., Iannotti, V., Luponio, C. \& Luponio Jr., C. 2004. State of the art and development trends of novel nanostructured elastomagnetic composites. Journal of Optoelectronics and Advanced Materials 6(2): 523-532.

Luheng, W., Tianhuai, D. \& Peng, W. 2009. Thin flexible pressure sensor array based on carbon black/silicone rubber nanocomposite. IEEE Sens. J. 9: 1130-1135.

Milaninia, K.M., Baldo, M.A., Reina, A. \& Kong, J. 2009. All graphene electromechanical switch fabricated by chemical vapor deposition. Applied Physics Letters 95(18): 183105.

Patil, S., Sinha, N. \& Melnik, R.V.N. 2009. Modeling of GaN/AlN heterostructure-based nano pressure sensors. In Nanoengineering Fabrication, Properties, Optics and Devices $I V$, edited by Dobisz, E.A. \& Eldada, L.A. San Diego: SPIE-The International Society for Optical Engineering. 74020C-8.

Poot, M. \& van der Zant, H.S.J. 2008. Nanomechanical properties of few-layer graphene membranes. Applied Physics Letters 92(6): 063111.

Singh, V., Sengupta, S., Solanki, H.S., Dhall, R., Allain, A., Dhara, S., Pant, P. \& Deshmukh, M.M. 2010. Probing thermal expansion of graphene and modal dispersion at lowtemperature using graphene nanoelectromechanical systems resonators. IOP Science Nanotechnology 21(16): 165204. 
Sorkin, V. \& Zhang, Y.W. 2011. Graphene-based pressure nanosensors. Journal of Molecular Modeling 17(11): 2825-2830.

Yao, H-B., Ge, J., Wang, C-F., Wang, X., Hu, W., Zheng, Z-J., Ni, Y. \& Yu, S-H. 2013. A flexible and highly pressuresensitive graphene-polyurethane sponge based on fractured microstructure design. Adv. Mater. 25(46): 6692-6698.
*Corresponding author; email: hingwah.lee@mimos.my

Received: 5 January 2017

Accepted: 6 March 2017

MIMOS Semiconductor (M) Sdn. Bhd

MIMOS Berhad

Technology Park Malaysia

57000 Kuala Lumpur, Federal Territory

Malaysia 